\title{
Surface modification of poly- $\varepsilon$-caprolactone electrospun fibrous scaffolds using plasma discharge with sputter deposition of a Ti target
}

\section{L.S. Barbarash ${ }^{a}$, E.N. Bolbasov ${ }^{b}$, L.V. Antonova ${ }^{a}$, V.G. Matveeva ${ }^{a}$, E.A. Velikanova ${ }^{a}$, E.V. Shesterikov ${ }^{b}$ Y.G. Anissimov ${ }^{c}$, S.I. Tverdokhlebov ${ }^{b^{*}}$}

a) Federal State Budgetary Institution "Research Institute for Complex Issues of Cardiovascular Diseases”, 6 Sosnovy Blvd, Kemerovo, 650002, Russian Federation.

b) Tomsk Polytechnic University, 30 Lenin Avenue, Tomsk, 634050, Russian Federation.

c) Griffith University, School of Natural Sciences, Engineering Dr., Southport, QLD 4222, Australia.

Corresponding author: Sergei I. Tverdokhlebov, e-mail: tverd@tpu.ru, phone: +7(3822)56-34-37, Tomsk Polytechnic University, 30 Lenin Avenue, Tomsk 634050, Russian Federation

\begin{abstract}
Poly- $\varepsilon$-caprolactone (PCL) biodegradable fibrous scaffolds were modified by plasma of magnetron discharge with titanium (Ti) target sputtering. The influence of the plasma treatment time on the structure and properties of the electrospun scaffolds was investigated. It was shown that increasing the plasma treatment time increases hydrophilicity of scaffolds by increasing the content of titanium and oxygen, as well as increasing the size and number of pores on the fibers surface without changing the mean diameter and volume fraction of the scaffolds. In vitro studies demonstrated that the plasma treatment within the chosen time intervals increases the adhesion of cells to the scaffolds, but at the same time it causes the decline in cell viability when increased to 9 minutes.
\end{abstract}

Keywords: biomaterials, poly- $\varepsilon$-caprolactone, fibrous scaffold, magnetron discharge, plasma treatment.

\section{Introduction.}

Poly- $\varepsilon$-caprolactone (PCL), a crystalline aliphatic polyester with a melting point $\left(T_{m}\right)$ of $60{ }^{\circ} \mathrm{C}$, is a promising material for a large range of the biomedical applications due to its rheological and viscoelastic properties [1].

Electrospinning is one of the most promising methods for the fabrication of scaffolds for the tissue and organ regeneration. Due to the high surface-to-volume ratio, highly interconnected porous structure and a great adjustability of electrospinning parameters such scaffolds are able to mimic the topology of the extracellular matrix (ECM) of a native human tissue [2]. 
PCL electrospun fibrous scaffolds are known for the high tensile strength and high elongation, and used as vascular grafts, drug delivery vehicles, in the fields of bone and cartilage tissue engineering, nerve regeneration, etc. [3]. The main limitation of the PCL electrospun scaffolds to their applications in tissue engineering is their low surface energy. It obstructs cell migration into the scaffold, their attachment, proliferation and viability consequently decreasing the "biocompatibility" of the scaffold [4].

It is known that an effective way to increase the biocompatibility of the scaffolds made of bioresorbable polymers is the treatment in the corona, dielectric barrier, radio frequency (RF) or microwave (MW) discharge plasmas [5,6]. A promising way to increase the biocompatibility of polymer scaffolds is treatment in a gas-discharge plasma of magnetron that occurs with sputter deposition of a solid state target, as it allows to change the chemical composition of the plasma not only by changing the composition of the atmosphere in the chamber, but also by changing the composition of the sputtering target $[7,8]$. It has previously been shown that magnetron discharge plasma surface treatment of films made of polylactic acid $\left(T_{m}=180-190{ }^{\circ} \mathrm{C}\right)$ and a copolymer of lactic and glycolic acid, increases the adhesion value indicators and the cell viability $[9,10]$. It was found that the effect of the plasma discharge on polymeric material is accompanied by a considerable heating of the surface, that can potentially destroy scaffold polymer [11]. Thus the thermal effects of magnetron plasma discharge is the factor potentially limiting the use of this type of plasma for modifying polymer scaffolds of bioresorbable polymers, especially polymers with a low melting point which is a focus of this study.

This letter reports the results of pilot studies demonstrating the ability to maintain the structure and increase the biocompatibility of 3D fibrous scaffolds made of polycaprolactone, which has a low melting point, when treated with a gas-discharge magnetron plasma.

\section{Materials and methods.}

PCL with molecular weight (Mw) 70000-90000 g/mol (Sigma, USA) was used to prepare a 9\% solution in chloroform $\left(\mathrm{CHCl}_{3}\right)$ (Ekros, Russia). Nanofibrous scaffolds were processed in Tomsk Polytechnic University (TPU) by using NANON-01A electrospinning machine (MECC Co., Japan). The electrospun nanofibers were deposited on a frame cylinder collector (diameter $100 \mathrm{~mm}$, length $210 \mathrm{~mm}$ ) rotating at $50 \mathrm{rpm}$. The solution flow rate was $6 \mathrm{~mL} /$ hour, applied voltage was $20 \mathrm{kV}$, and the distance between the needle tip and the collector was $190 \mathrm{~mm}$. 
The fibrous PCL scaffolds were plasma treated in TPU by magnetron discharge with sputter deposition of a $\mathrm{Ti}$ target in the atmosphere of argon under constant current. The modification was operated within $33 \mathrm{~mm}$ between the fibrous scaffolds and the magnetron under pressure of $0.8 \mathrm{~Pa}$ in argon with voltage of $200 \mathrm{~V}$ and discharge current of $0.2 \mathrm{~A}$. The plasma treatment was maintained in a cyclic mode (on 1 minute with off 3 minutes) in order to decrease the temperature impact on the scaffolds. Thus, 4 groups of the modified fibrous scaffolds being plasma treated for 1, 3, 6 and 9 min respectively were obtained.

Topology of the fibrous scaffolds was studied with scanning electron microscopy (SEM) (Quanta 400 FEI, USA). Nanofiber diameters were measured with ImageJ 1.38 software (National Institute of Health, USA). The volume fraction was calculated with a method described by Sell et al. [12] as a ratio of the fibrous scaffold's density to the density of the film fabricated from the same polymer solution.

The study of the chemical composition of the samples was carried out using Energy Dispersive Spectroscopy (EDS, Genesis 4000, EDAX). Glycerol, highly viscous polar liquid, was used to characterize the differences in contact angle of the modified fibrous scaffolds [13]. The research was carried out by a sit-drop method (Easydrop, Germany) 1 minute after a liquid droplet was placed on the sample.

Assessment of the plasma treatment influence on the cell adhesion and viability were performed using human endothelial hybrid cell line EA-hy 926 provided by Cora-Jean S. Edgell (University of North Carolina, USA). For this purpose cell cultures were placed in 24 well plate, with well measuring 10 $\times 10 \mathrm{~mm}, 2 \times 10^{5}$ cells per well. Cells were cultured for 6 days in accordance with the protocol described by Emeis et al. [14]. Cells adhesion evaluation was performed in Federal State Budgetary Institution “Research Institute for Complex Issues of Cardiovascular Diseases” using non-specific dyes PKH26 and Hoechst 33342 (Sigma Aldrich, USA). Cells were labelled with specific dyes Acridine Orange (BioOptica, Italy) and Ethidium Bromide (Sigma Aldrich, USA) for the viability evaluation. Orange colour of the nuclei inside cells for the latter staining evidenced dead cells, and green colour corresponded to living, metabolically active cells. Untreated scaffolds were used as control samples. The study was maintained using the inverted live cell imaging microscope Axio Observer Z1 (Carl Zeiss, Germany). The efficiency of cell adhesion and viability was evaluated by the number of cells visible within ten microscope 
viewfinders, averaged and normalised to $1 \mathrm{~mm}^{2}$. Studies were conducted using six samples of each of the test groups.

\section{Results and discussions.}

Fig. 1 shows the results of studies for stock PCL samples (Fig. 1 a), plasma-modified samples

(Fig. 1 b-e), SEM images, fluorescent map of labelled cells and wettability images of glycerol droplets.
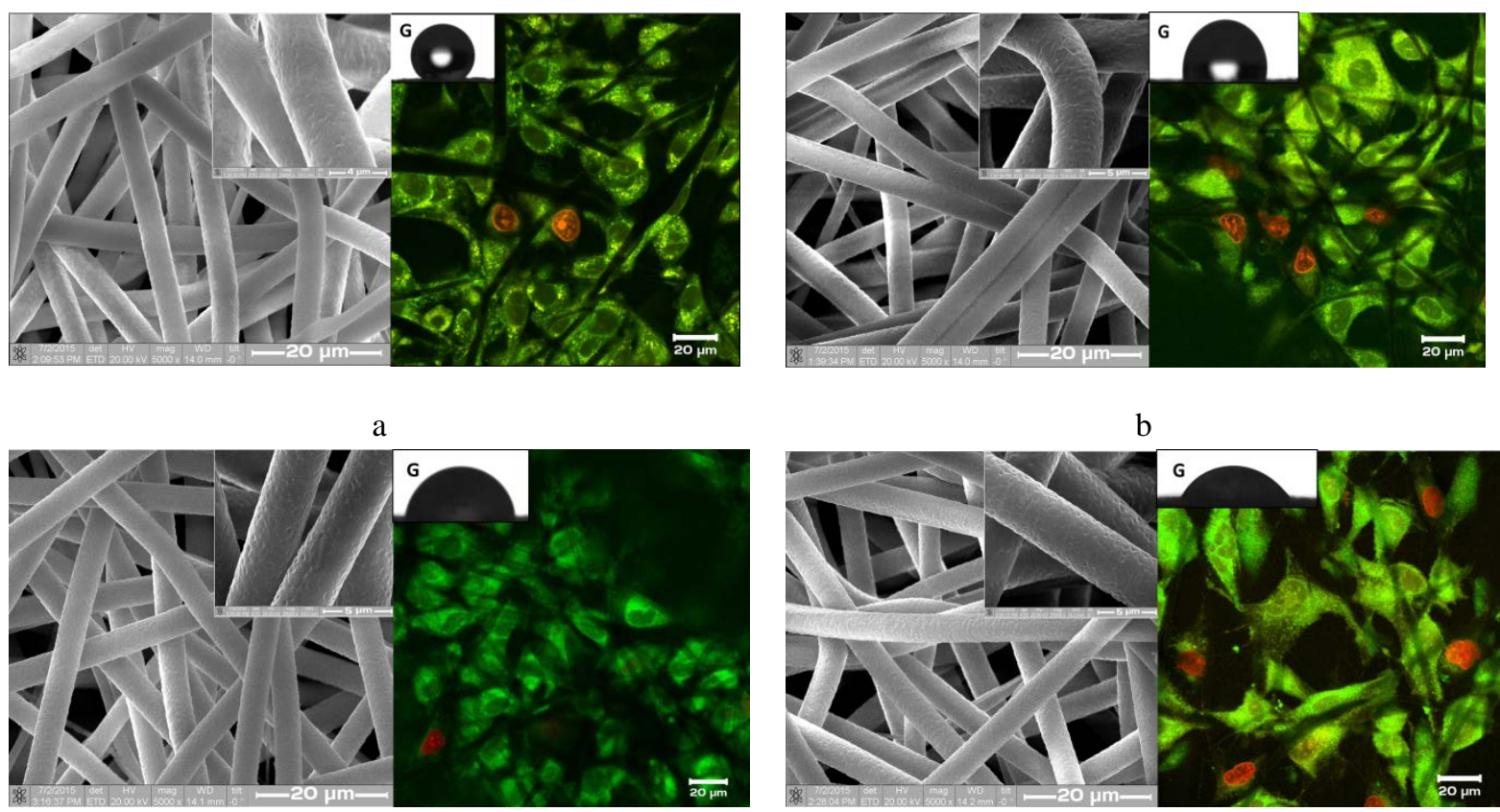

C

d

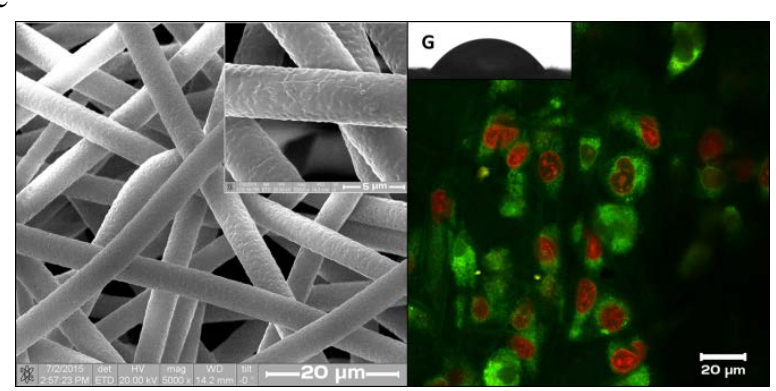

e

Fig 1. SEM images, fluorescent map of labelled cells (live green cells (acridine orange), orange nucleus of dead cells (ethidium bromide)) and wettability for PCL samples for (a) untreated, and treaded in plasma for (b) 1 min, (c) 3 min, (d) 6 min, (e) 9 min.

The resulting fibrous scaffolds consist of distinct cylindrical fibers that are chaotically entangled between each other (Fig. 1a). Mean value of volume fraction was $14.6 \pm 1.4 \%$, indicating high porosity of formed fibrous scaffolds. This high porosity supports cell migration and nutrient transport, particularly in 
an electrospun structure where all void spaces are interconnected. Fiber diameters are normally distributed with a mean diameter of $4.3 \pm 0.3 \mu \mathrm{m}$. The images of greater magnification in the range $\times$ (20000-24000) revealed that the surface of the fibers had its own relief with single pores of $0.28 \pm 0.04$ $\mu$ diameter (Fig 1a).

Table 1. Chemical composition, contact angle, number and pore size on the fibrous surface, PCL scaffolds at different plasma exposure.

\begin{tabular}{|c|l|l|c|c|c|c|}
\hline $\begin{array}{c}\text { Treat } \\
\text { ment } \\
\text { time, } \\
\text { min }\end{array}$ & \begin{tabular}{l} 
Pore size, \\
\cline { 2 - 6 }
\end{tabular} & $\begin{array}{l}\text { Number of } \\
\text { pores, } \\
\text { unit/ } \mu^{2}\end{array}$ & \multicolumn{3}{|c|}{ Chemical composition, At. \% } & $\begin{array}{l}\text { Contact } \\
\text { angle, deg }\end{array}$ \\
\hline 0 & $0.28 \pm 0.04$ & $0.9 \pm 0.1$ & $82.7 \pm 0.5$ & $17.3 \pm 0.6$ & - & $128 \pm 3$ \\
\hline 1 & $0.32 \pm 0.05^{*}$ & $1.1 \pm 0.1^{*}$ & $82.3 \pm 0.6$ & $17.6 \pm 0.7$ & $\approx 0.1$ & $110 \pm 4^{*}$ \\
\hline 3 & $0.36 \pm 0.04^{*}$ & $1.4 \pm 0.2^{*}$ & $81.8 \pm 0.6^{*}$ & $17.7 \pm 0.5$ & $0.4 \pm 0.2^{*}$ & $98 \pm 4^{*}$ \\
\hline 6 & $0.41 \pm 0.06^{*}$ & $1.5 \pm 0.2^{*}$ & $80.4 \pm 0.4^{*}$ & $18.7 \pm 0.7^{*}$ & $1.0 \pm 0.4^{*}$ & $93 \pm 3^{*}$ \\
\hline 9 & $0.45 \pm 0.05^{*}$ & $1.7 \pm 0.2^{*}$ & $79.3 \pm 0.6^{*}$ & $18.8 \pm 0.4^{*}$ & $1.9 \pm 0.4^{*}$ & $87 \pm 3^{*}$ \\
\hline
\end{tabular}

Droplets, junctions, bundles, variable thickness fibers or beads were not observed for all treatment times (Fig. 1 b-e). Mean value of volume fraction and mean diameter of fibers were also similar for all treatment times. Thus, with the selected treatment parameters there is no significant destructive changes in scaffolds' macrostructures. With the increase in processing time of the magnetron discharge plasma treatment increases the number and size of pores on the fiber surface, which is equivalent to an increase in their surface area (Table 1. Fig. 1 b-e). Increase in the number and size of pores on the fiber surface is due to the degradation processes of the polymer surface under the influence of high-energy particles in the plasma. An increase in PCL films roughness after exposure to the RF plasma discharge was noted in [15]. Since the PCL structure typically consists of crystalline and amorphous regions, the increase in surface roughness is probably due to the destruction of mostly amorphous regions of the polymer that are less resistant to plasma attack.

The plasma treatment leads to changes in the chemical composition of the PCL scaffolds. With increasing treatment time, an increase in the content of titanium and oxygen in scaffold structure is evident (Table 1). The increase in oxygen content in the PCL scaffold is caused by replacement of C-C and / or $\mathrm{C}-\mathrm{H}$ bonds with $\mathrm{C}-\mathrm{O}, \mathrm{O}-\mathrm{C}=\mathrm{O}$ and $\mathrm{C}=\mathrm{O}$ functional groups $[16,17]$ and with surface saturation 
by $\mathrm{OH}$ and - $\mathrm{COOH}$ functional groups [15], as well as titanium oxidation in air. The increase in the number of functional groups containing oxygen increases the hydrophilicity of scaffolds as evidenced by the decrease in contact angle of scaffolds (Table 1). Thus, treatment with the magnetron discharge plasma improves contact properties of scaffolds and stimulates endothelial cell attachment to PCL scaffolds as evidenced by a significant increase in the cell population density in comparison with the untreated scaffolds (Table 2).

Table 2. Cell population density and relative number of viable cells in population for cells from the line EA-hy 926 on the PCL fibrous scaffolds for different plasma treatment times.

\begin{tabular}{ccc}
\hline $\begin{array}{c}\text { Treatment time, } \\
\text { min }\end{array}$ & $\begin{array}{c}\text { Cell population } \\
\text { density, } \mathrm{mm}^{-2}\end{array}$ & $\begin{array}{c}\text { Relative number of viable } \\
\text { cells in population, \% }\end{array}$ \\
\cline { 2 - 3 } $\mathrm{n}=6 . \mathrm{Me}(25 \% ; 75 \%)$ \\
\hline 0 & $1546(1529 ; 1647)$ & $97.2(96.7 ; 97.4)$ \\
\hline 1 & $2250(2173 ; 2313)^{*}$ & $94.5(77.7 ; 98.1)$ \\
\hline 3 & $1999(1913 ; 2084)^{*}$ & $98.3(97.2 ; 98.9)$ \\
\hline 6 & $1642(1588 ; 1665) *$ & $93.6(92.3 ; 94.9)$ \\
\hline 9 & $2042(1979 ; 2441)^{*}$ & $79.0(77.7 ; 90.5) *$ \\
\hline 0.05 compared to the control sample
\end{tabular}

Treatment with the magnetron discharge plasma for 1 to 6 minutes does not cause significant changes in the relative number of viable cells in comparison with the untreated sample (Table 2. Fig 1 a d (2D fluorescence of labeled cells)). Reduction in the relative number of viable cells is observed for 9 minutes treatment time (Table 2. Fig 1 e (2D fluorescence of labeled cells)). This reduction is probably due to a higher level of saturation of the surface layers of fibrous scaffolds with low molecular weight toxic products of degradation of the polymer material and / or complex chemical compounds with titanium. During cell culturing the toxic products from the culture medium may adhere to a cellular membrane and impede a cellular metabolism or inhibit cellular life processes by directly diffusing through the membrane into cells.

\section{Conclusion.}

This work demonstrated the possibility of using the treatment with magnetron plasma discharge occurring during sputtering of a titanium target in an argon atmosphere to modify a fibrous scaffold fabricated from bioresorbable polymeric materials with low melting point. It was shown that the plasma treatment does not cause destructive changes in the scaffold's microstructure and that increasing the 
plasma treatment time increases the hydrophilicity of the scaffold and its saturation with oxygen and titanium. It was found that up to 6 minute treatment time the relative number of viable cells in population does not decrease significantly and there is increase in cell population density, suggesting better cellular adhesion together with high cellular viability.

\section{Acknowledgments}

This investigation was performed in the Research Institute for Complex Issues of Cardiovascular

Diseases owing to the funding of Russian Science Foundation (project № 14-25-00050).

\section{References}

[1] Woodruff MA, Hutmacher DW. The return of a forgotten polymer-Polycaprolactone in the 21st century. Prog Polym Sci 2010;35:1217-56. doi:10.1016/j.progpolymsci.2010.04.002.

[2] Jiang T, Carbone EJ, Lo KW-H, Laurencin CT. Electrospinning of Polymer Nanofibers for Tissue Regeneration. Prog Polym Sci 2014;46:1-24. doi:10.1016/j.progpolymsci.2014.12.001.

[3] Dash TK, Konkimalla VB. Poly-e-caprolactone based formulations for drug delivery and tissue engineering: A review. J Control Release 2012;158:15-33. doi:10.1016/j.jconrel.2011.09.064.

[4] Sridhar R, Venugopal JR, Sundarrajan S, Ravichandran R, Ramalingam B, Ramakrishna S. Electrospun nanofibers for pharmaceutical and medical applications. J Drug Deliv Sci Technol 2011;21:451-68. doi:10.1016/S1773-2247(11)50075-9.

[5] Siow KS, Britcher L, Kumar S, Griesser HJ. Plasma methods for the generation of chemically reactive surfaces for biomolecule immobilization and cell colonization - A review. Plasma Process Polym 2006;3:392-418. doi:10.1002/ppap.200600021.

[6] Desmet T, Morent R, De Geyter N, Leys C, Schacht E, Dubruel P. Nonthermal plasma technology as a versatile strategy for polymeric biomaterials surface modification: A review. Biomacromolecules 2009;10:2351-78. doi:10.1021/bm900186s.

[7] Kelly P., Arnell R. Magnetron sputtering: a review of recent developments and applications. Vacuum 2000;56:159-72. doi:10.1016/S0042-207X(99)00189-X.

[8] Klinger L, Shtansky DV, Levashov EA, Rabkin E. Kinetic model of co-deposition of thin multicomponent films. Mater Lett 2015;156:118-20. doi:10.1016/j.matlet.2015.05.013.

[9] Ryu GH, Yang W-S, Roh H-W, Lee I-S, Kim JK, Lee GH, et al. Plasma surface modification of poly (d,l-lactic-co-glycolic acid) (65/35) film for tissue engineering. Surf Coatings Technol 2005;193:60-4. doi:10.1016/j.surfcoat.2004.07.062.

[10] Bolbasov EN, Rybachuk M, Golovkin AS, Antonova LV, Shesterikov EV, Malchikhina AI, et al. Surface modification of poly(l-lactide) and polycaprolactone bioresorbable polymers using RF plasma discharge with sputter deposition of a hydroxyapatite target. Mater Lett 2014;132:281-4. doi:10.1016/j.matlet.2014.06.115.

[11] Tverdokhlebov SI, Bolbasov EN, Shesterikov EV, Antonova LV, Golovkin AS, Matveeva VG, et al. Modification of polylactic acid surface using RF plasma discharge with sputter deposition of a hydroxyapatite target for increased biocompatibility. Appl Surf Sci 2015;329:32-9. doi:10.1016/j.apsusc.2014.12.127.

[12] Sell S, Barnes C, Simpson D, Bowlin G. Scaffold permeability as a means to determine fiber diameter and pore size of electrospun fibrinogen. J Biomed Mater Res - Part A 2008;85:115-26. 
doi:10.1002/jbm.a.31556.

[13] Martins A, Pinho ED, Faria S, Pashkuleva I, Marques AP, Reis RL, et al. Surface Modification of Electrospun Polycaprolactone Nanofiber Meshes by Plasma Treatment to Enhance Biological Performance. Small 2009:NA - NA. doi:10.1002/smll.200801648.

[14] Emeis JJ, Edgell CJ. Fibrinolytic properties of a human endothelial hybrid cell line (Ea.hy 926). Blood 1988;71:1669-75.

[15] Lee H-U, Jeong Y-S, Jeong S-Y, Park S-Y, Bae J-S, Kim H-G, et al. Role of reactive gas in atmospheric plasma for cell attachment and proliferation on biocompatible poly $\varepsilon$-caprolactone film. Appl Surf Sci 2008;254:5700-5. doi:10.1016/j.apsusc.2008.03.049.

[16] Jacobs T, Declercq H, De Geyter N, Cornelissen R, Dubruel P, Leys C, et al. Improved cell adhesion to flat and porous plasma-treated poly- $\varepsilon$-caprolactone samples. Surf Coatings Technol 2013;232:447-55. doi:10.1016/j.surfcoat.2013.06.001.

[17] Jacobs T, De Geyter N, Morent R, Desmet T, Dubruel P, Leys C. Plasma treatment of polycaprolactone at medium pressure. Surf Coatings Technol 2011;205:S543-7. doi:10.1016/j.surfcoat.2011.02.012. 